\title{
Pseudotumoural soft tissue lesions of the foot and ankle: a pictorial review
}

\author{
Erik Van Hul • Filip Vanhoenacker • Pieter Van Dyck • \\ Arthur De Schepper • Paul M. Parizel
}

Received: 29 October 2010 / Accepted: 15 February 2011 /Published online: 1 May 2011

(C) European Society of Radiology 2011

\begin{abstract}
In the foot and ankle region, benign neoplasms and pseudotumoural soft tissue lesions are significantly more frequent than malignant tumours. The pseudotumoural lesions constitute a heterogeneous group, with highly varied aetiology and histopathology. This article reviews the imaging features of the most common pseudotumours of the soft tissues in the foot and ankle. Although the imaging characteristics of several of the lesions discussed are non-specific, combining them with lesion location and clinical features allows the radiologist to suggest a specific diagnosis in most cases.
\end{abstract}

Keywords Pseudotumours · Ankle · Foot · MRI · Soft tissue

\section{Introduction}

Soft tissue lesions of the foot and ankle are a relatively rare cause of referral for medical imaging. They include benign and malignant neoplasms, as well as non-neoplastic or pseudotumoural lesions. In the foot, only a small number of

\footnotetext{
E. Van Hul · F. Vanhoenacker $\cdot$ P. Van Dyck $\cdot$ A. De Schepper · P. M. Parizel

Department of Radiology, Antwerp University Hospital,

University of Antwerp,

Wilrijkstraat, 10 ,

2650 Edegem, Belgium

E. Van Hul

e-mail: erikvanhul@hotmail.com

F. Vanhoenacker $(\bowtie)$

Department of Radiology, AZ Sint-Maarten,

Rooienberg 25,

2570 Duffel, Belgium

e-mail: filip.vanhoenacker@telenet.be
}

soft tissue lesions prove to be malignant. Synovial sarcoma, clear cell sarcoma, leiomyosarcoma, fibrosarcoma and malignant fibrous histiocytoma are the most frequent malignancies. Benign tumours include deep fibromatosis, neurogenic tumours, lipoma, haemangioma and synovial proliferations (pigmented villonodular synovitis - giant cell tumour of the tendon sheath and synovial osteochondromatosis). The pseudotumoural lesions of the foot comprise a diverse group with widely varying histopathology; they include, among others, ganglion and synovial cysts, intermetatarsal and adventitious bursitis, epidermoid cysts, inflammatory lesions (gout tophi and rheumatoid nodules), Morton's neuroma and granuloma annulare. Aetiopathogenesis of these lesions is varied, but, in general, degenerative, inflammatory and infectious phenomena may play a role. The aim of this article is to give a comprehensive overview of the most common pseudotumoural lesions of the foot and their respective imaging features.

\section{Accessory muscles}

Accessory muscles are congenital anatomical variants that may clinically simulate soft tissue lesions with mass effect. The most frequently encountered accessory muscles of the foot and ankle are the flexor digitorum accessorius longus (FDAL), accessory soleus (Fig. 1), peroneus quartus (Fig. 2) and peroneocalcaneus internus [1].

The presence of an FDAL, and less frequently of an accessory soleus, may be associated with tarsal tunnel syndrome $[2,3]$.

Ultrasound shows a hypoechogenic structure with a typical striated appearance of muscle. Dynamic ultrasound with active muscle contraction will show changes in the shape of the mass. On magnetic resonance (MR) imaging, 


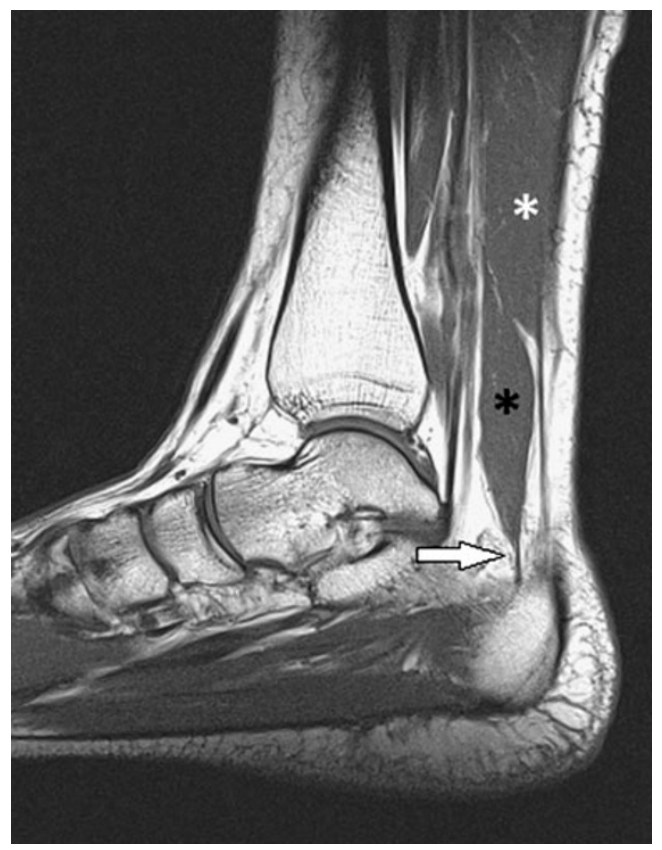

Fig. 1 Accessory muscle. Sagittal T1-WI. An accessory soleus (black asterisk) is seen anterior-inferior to the soleus muscle (white asterisk), arising from the tibia (origin not shown) and with a tendinous insertion onto the superior surface of the calcaneus anteromedial to the Achilles tendon (arrow). This is just one of the five types of accessory soleus that have been described on the basis of insertion characteristics

accessory muscles are isointense to other muscle tissue on all pulse sequences [1].

\section{Ganglion and synovial cyst}

The terminology of these cystic lesions is confusing, and in clinical practice the terms "synovial cyst" and "ganglion cyst" are sometimes used interchangeably.

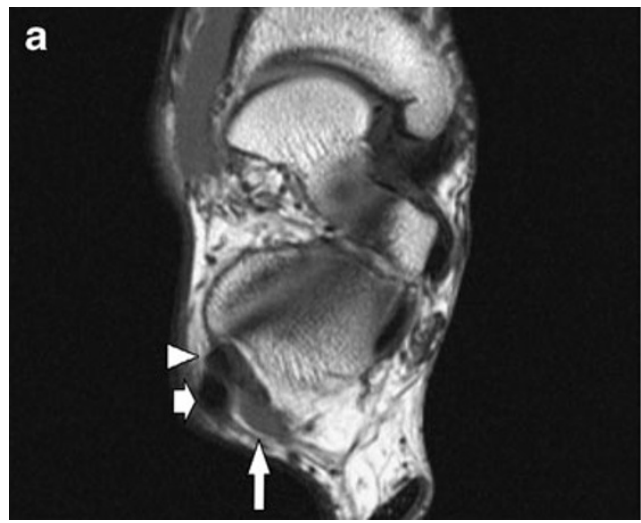

Fig. 2 Accessory muscle: peroneus quartus. Axial T1-WI at the level of the subtalar joint (a) and slightly below (b). Peroneus quartus (long arrow) positioned posteromedial to tendons of the long (short arrow) and short (arrowhead) peroneal muscle. Several types of peroneus
The term "synovial cyst" describes a continuation or herniation of the synovial membrane through the joint capsule. It consists of a fluid collection, lined by a continuous layer of "true" synovial cells. There is always communication with the adjacent joint. Usually, associated joint disease is present, like osteoarthrosis, inflammatory and post-traumatic joint diseases.

A ganglion cyst also contains a mucinous fluid, but the wall consists of a discontinuous layer of flattened pseudosynovial cells, surrounded by connective tissue. Communication with the adjacent joint is not always present. There remains much controversy in the literature concerning the pathogenesis of ganglion cysts. According to the synovial herniation theory, a ganglion cyst represents an advanced stage of a degenerated synovial cyst, in which the continuous synovial lining and the communication with the joint may be lost during the process of degeneration [4].

Ganglion and synovial cysts are the most common soft tissue lesions in the ankle and foot region, most frequently located around the ankle or at the dorsum of the foot. In the ankle and foot region, they are more frequently associated with symptoms similar to those of lesions at the wrist [5]. Clinically, local pain, limited joint mobility or nerve entrapment (e.g. in the tarsal tunnel) may be present due to mass effect [6].

The role of imaging is to define the cystic nature and exact location of the lesion, and to demonstrate possible communication with a joint or tendon sheath, which is relevant for optimal treatment planning.

On ultrasound examination, ganglion and synovial cysts appear as round to oval, monoloculated or multiloculated anechogenic lesions, with posterior acoustic enhancement (Fig. 3). Cysts complicated by chronic inflammation, infection or haemorrhage can however demonstrate partially or completely hyperechogenic content. A communicating

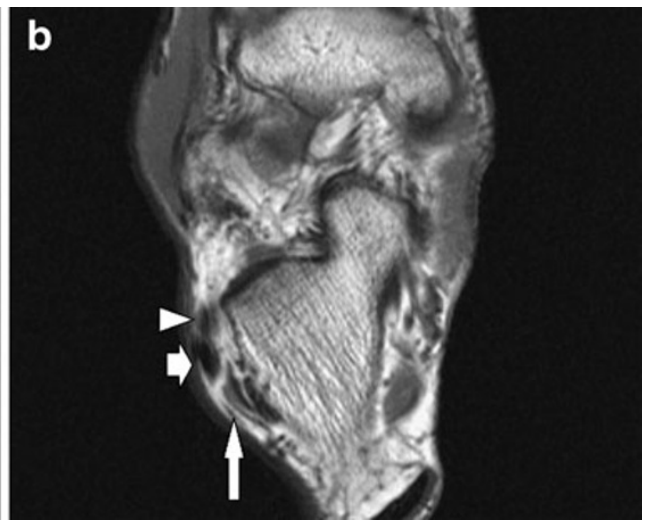

quartus are described based on the distal insertion, which can be onto the peroneal tubercle or the retrotrochlear eminence of the calcaneus, and less frequently the cuboid, the peroneus longus or the inferior peroneal retinaculum 

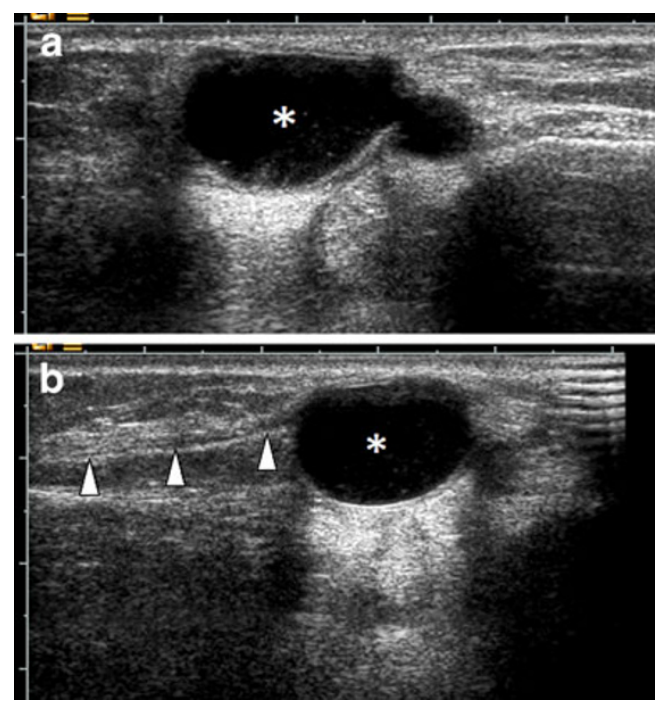

Fig. 3 Synovial cyst. A 34-year-old female patient with lateral foot pain and soft tissue mass posterior to the lateral malleolus. Ultrasound examination in the paracoronal (a) and coronal plane (b) demonstrates a well-circumscribed, bilobular, mostly anechogenic lesion (asterisk) with posterior acoustic enhancement, correlating with a cystic nature. Some echogenic debris is present in the dependent part of the lesion. The lesion causes displacement of the sural nerve (arrowheads), causing lateral foot pain

stalk with the joint or tendon sheath often cannot be detected with ultrasound alone.

The MR features of ganglion and synovial cysts are those typical of cystic lesions (Fig. 4): hypo-intense or isointense to muscle on T1-weighted images (WI) and homogeneous high signal intensity (SI) on T2-WI. There is a faint rim enhancement of the cyst wall after gadolinium contrast medium administration. Typical cystic appearance can be altered in the case of haemorrhage or chronic inflammation, with higher SI on T1-WI and lower SI on T2-WI, along with thickening and increased contrast enhancement of the cyst wall.

Even with MR imaging, identification of a communicating stalk with the joint or tendon sheath may be difficult. In these cases, CT arthrography with delayed imaging may be performed to ultimately demonstrate communication [7].

\section{Morton's neuroma (fibroma)}

Morton's neuroma, or interdigital neuroma, is, despite its name, not a true neuroma but perineural fibrosis and nerve degeneration [8], most likely due to repetitive compression and irritation of the interdigital nerve. Therefore, the term Morton's fibroma is preferred. Morton's fibromas are most commonly found in the second and third intermetatarsal spaces, and less frequently in the first and fourth. Also, more than one intermetatarsal space may be affected.

Morton's fibroma is most commonly diagnosed in middle age, with a higher prevalence in women, and is believed to be related to the use of high-heeled shoes with increased weight bearing on the forefoot [9].

Although Morton's fibroma is a common cause of intermetatarsalgia, in many cases it is not associated with clinical symptoms. Lesions with a transverse diameter smaller than $5 \mathrm{~mm}$ are often asymptomatic, as studies on healthy volunteers have shown, with a prevalence of small $(<5 \mathrm{~mm})$ Morton's fibromas of approximately $30 \%$ in asymptomatic individuals [10]. Lesions with a transverse diameter of $5 \mathrm{~mm}$ or more are most likely symptomatic.
Fig. 4 Synovial cyst. Same patient as in Fig. 3. Coronal fat-suppressed T2-WI (a) and sagittal T1-WI (b): wellcircumscribed, bilobar lesion (asterisk) with high signal intensity (SI) on T2-WI and low SI on T1-WI. The smaller "lobe" (long arrow) extends caudally towards the posterior facet of the subtalar joint. The cyst causes displacement of the small saphenous vein (short arrow)
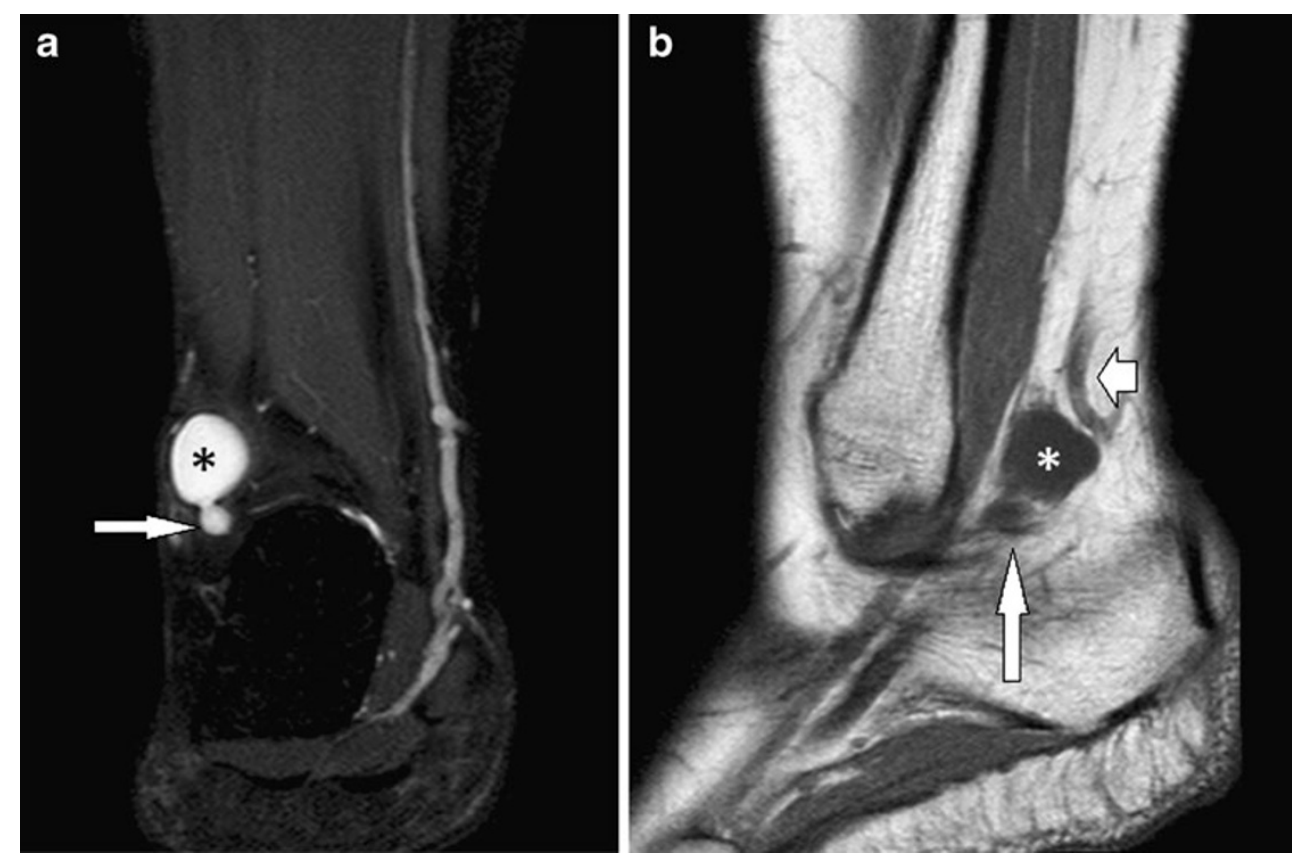
When a smaller lesion is detected, it might not be the cause of the patient's symptoms, and other pathological conditions (e.g. intermetatarsal bursitis, stress fracture, true neuroma) should be excluded [11].

Ultrasound examination is reliable in detecting Morton's fibroma [8] and evaluation reveals a well-defined hypoechoic mass in the plantar soft tissues at the level of the metatarsal heads. However, distinction of Morton's fibroma from an accompanying enlarged intermetatarsal bursa can be difficult, and lead to an overestimation in size [12]. Dynamic ultrasound examination using Mulder's test can increase conspicuity and diagnostic confidence. For this test, the patient's forefoot is held in the sonographer's nonimaging hand while performing lateral compression of the metatarsals, and applying the transducer to the plantar aspect of the intermetatarsal regions. When this manoeuvre is performed on patients with a Morton's fibroma, the mass is compressed between the metatarsal heads eliciting characteristic pain before it is plantarily displaced, often coinciding with a palpable click (Mulder's sign). This displacement allows ultrasound visualisation of otherwise occult lesions as well as more reliable measurement of small lesions [13].

MR imaging has been proven to be highly sensitive and specific in diagnosing Morton's fibroma, as well as providing an accurate preoperative assessment [14].

On short-axis MR images, Morton's fibroma appears typically as a tear-shaped, spindle-shaped or dumbbellshaped lesion in the region of the neurovascular bundle on the plantar side of the deep intermetatarsal ligament (Fig. 5). Sagittal images reveal a widening of the interdigital nerve. Morton's fibromas display typical signal intensities on MR imaging sequences: isointense to muscle on T1-WI and hypointense relative to fat tissue on T2-WI [15]. There is no typical enhancement pattern on (fat-suppressed) T1-WI after intravenous administration of gadolinium contrast medium, varying from low to moderate to marked enhancement. In the appropriate clinical setting, administration of gadolinium contrast medium is not required for a reliable diagnosis of a Morton's fibroma.

\section{Bursitis}

Intermetatarsal bursa/bursitis

Inflammation of the intermetatarsal bursae is a known cause of metatarsalgia. The intermetatarsal bursa is a naturally occurring synovium-lined cavity between the metatarsal heads containing a small amount of lubricating fluid, located immediately dorsal to the deep transverse metatarsal ligament. This bursa is normally present in the first through fourth intermetatarsal space [16]. Studies in asymptomatic
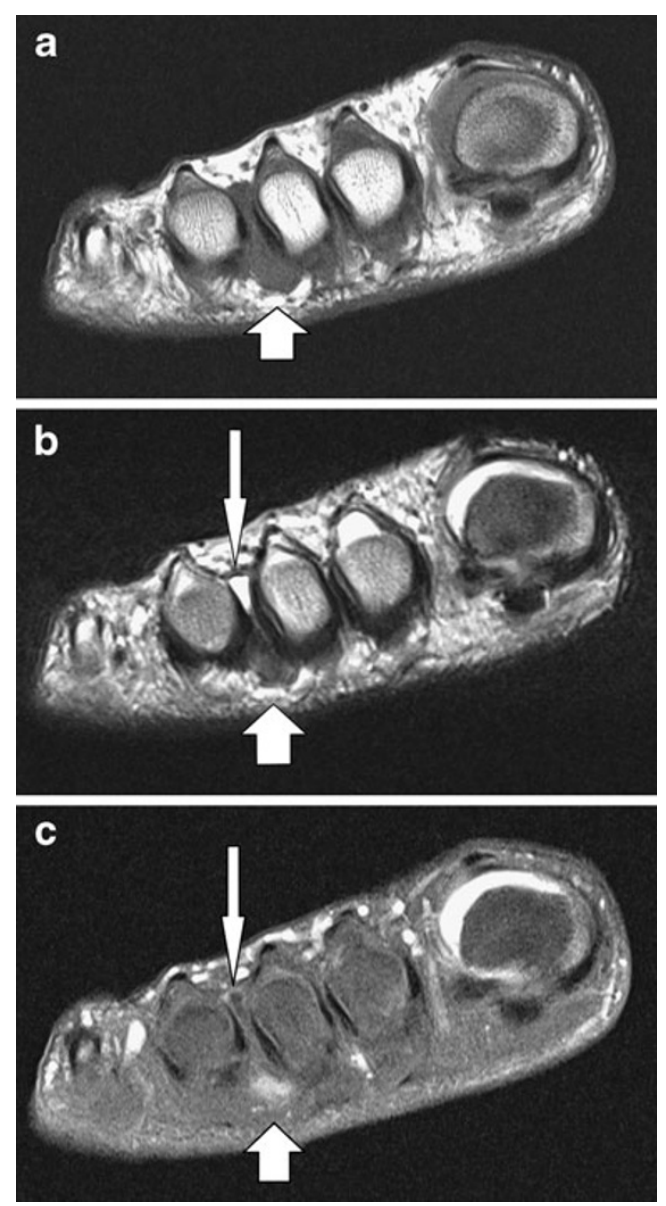

Fig. 5 Morton's neuroma (fibroma). Short-axis T1-WI (a), T2-WI (b) and fat-suppressed contrast-enhanced T1-WI (c): spindle-shaped lesion at the third intermetatarsal space (short arrow), located plantar to the deep transverse intermetatarsal ligament, with low SI on T1-WI and T2-WI. Overestimation in size on T1-WI due to associated (hypointense) fluid in the intermetatarsal bursa (long arrow), revealed as hyperintense on T2-WI. There is moderate contrast enhancement of the fibroma, as well as some rim enhancement of the bursa

volunteers have shown that demonstration of a small amount of fluid in the bursae of the first through third intermetatarsal space on MR imaging cannot be considered a sign of bursitis. A transverse diameter greater than $3 \mathrm{~mm}$ of these bursae has been proposed as a cut-off value for suggesting intermetatarsal bursitis. However, demonstration of fluid in the fourth intermetatarsal space always appears to be connected to clinical symptoms [12].

Although the exact pathogenesis of intermetatarsal bursitis is unclear, it is thought to be the result of chronic mechanical compression and irritation between the metatarsal heads, similar to the suspected pathogenesis of Morton's neuroma [17]. It is thus unsurprising that these disorders are frequently associated (Fig. 5).

MR imaging demonstrates a well-defined fluid collection at a typical location between the metatarsal heads with low SI on T1-WI and high SI on T2-WI. Subtle peripheral 
enhancement is seen following intravenous administration of gadolinium contrast medium [18].

\section{Adventitious bursitis}

Adventitious bursae may develop in adulthood at sites where subcutaneous tissue is exposed to high pressure and friction [19]. Under these conditions formation of a subcutaneous adventitious bursa starts as a coalescence of pre-existing small spaces in loose connective tissue. The walls progressively become differentiated from the adjacent connective tissue and a well-defined fluid-filled cavity is formed, which is lined by synovium-like columnar cells [20]. Unlike permanent bursae, which serve to reduce friction between skin and adjacent bony protuberances (e.g. over the olecranon), they lack a mesothelial lining [4].

In the foot and ankle, adventitious bursae may develop almost anywhere, usually adjacent to bony prominences. The most common locations are over the medial aspect of the first metatarsal head and plantar to the metatarsal heads.

MR imaging (Fig. 6) demonstrates an ill-defined lesion in the subcutaneous fat which is of low SI on T1-WI, and high SI on T2-WI, consistent with the enclosed fluid, often with intralesional string- or band-like structures with low SI $[21,22]$.

Although plantar fat pad alterations under the first and fifth metatarsal heads are a common incidental finding on MR imaging in asymptomatic volunteers, these are smaller than those in symptomatic individuals. These asymptomatic alterations are of low SI on T1-WI and T2-WI, and are believed to represent reactive fibrous tissue induced by mechanical stress (see "Miscellaneous disorders-Diabetic callus") [22].

\section{Cutaneous and subcutaneous lesions}

\section{Epidermoid cyst}

An epidermoid cyst results from the proliferation of keratinproducing epidermal cells within a circumscribed space of the dermis. Histologically, an epidermoid cyst appears as a keratin-containing cyst lined with surface epidermis. The source of this epidermis is nearly always the infundibulum of a hair follicle [23].

Epidermoid cysts are, therefore, most common in the hair-bearing parts of the body, such as the scalp, face, trunk and scrotum. Occurrence in the extremities is less frequent, and thought to be due to traumatic implantation of epidermal tissue in the dermis. As a consequence, the most common location in the foot is at the plantar or medial aspect of the first metatarsal head [24].
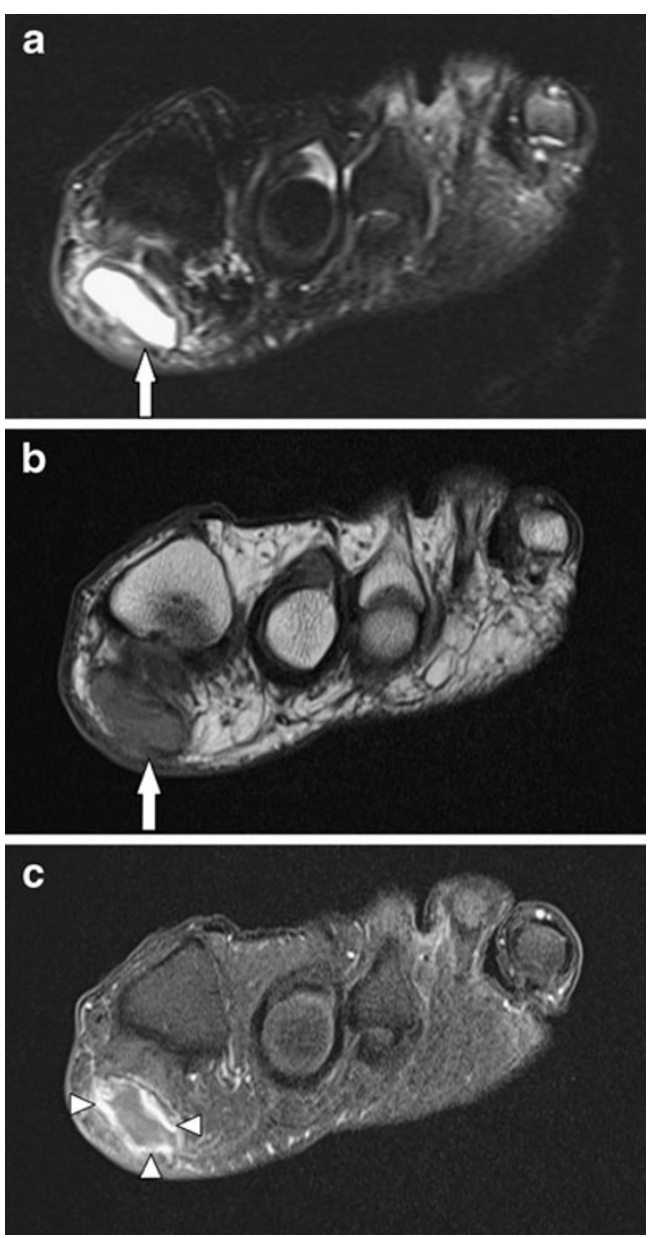

Fig. 6 Adventitious bursitis. A 54-year-old patient with a painful swelling located plantar to the first metatarsophalangeal joint. Shortaxis fat-suppressed T2-WI (a), T1-WI (b) and fat-suppressed contrastenhanced T1-WI (c): fluid collection plantar-medial to the first metatarsal head (long arrow) of high SI on T2-WI, and low SI on T1-WI, corresponding to a fluid-filled cavity. There is marked rim enhancement (arrowheads)

On ultrasound, an uncomplicated epidermoid cyst displays as an ovoid or spherical hypoechoic mass containing variable echogenic foci with posterior acoustic enhancement, without colour Doppler signals (Fig. 7). The scattered echogenic reflectors in the cyst are related to the lamellation of keratin debris. A ruptured epidermal cyst, however, may have lobulated contours and show colour Doppler signals, mimicking a solid mass [25].

On MR imaging (Fig. 8), an unruptured epidermoid cyst appears as a unilocular well-defined lesion, isointense or slightly hyperintense to muscle on T1-WI. Signal intensity on T2-WI is high, although irregular areas of low SI, reflecting the presence of dependent debris, are frequently noted $[24,26]$. After intravenous administration of gadolinium contrast medium epidermoid cysts display faint wall enhancement [27]. 

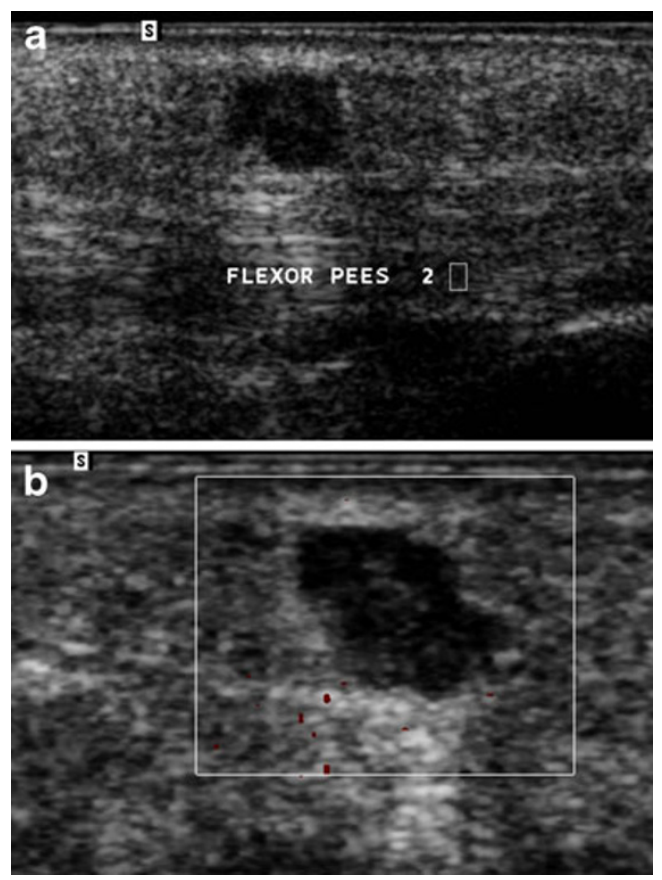

Fig. 7 Ultrasound of epidermoid cyst on the sole of the foot. The ultrasound images demonstrate a hypoechogenic polylobular lesion with posterior acoustic enhancement containing some scattered echogenic reflective material. The cyst is located in the subcutaneous fat superficial to the flexor tendon of the second digit

If an epidermoid cyst ruptures, the cyst contents are released into the dermis, with formation of a keratin granuloma [28]. Ruptured epidermoid cysts tend to present as multilocular lesions, with enhancement of the cyst wall due to fibrosis and giant-cell reaction to keratin, possibly mimicking malignancy [29].

\section{Granuloma annulare}

Granuloma annulare (GA) represents a group of benign dermatoses of unknown aetiology which include cutaneous (localised, generalised or perforating) and subcutaneous types. This last type is referred to as subcutaneous granuloma annulare (SGA), occasionally also referred to as pseudorheumatoid nodule.

Histologically, SGA consists of a palisading granuloma with a small area of central necrosis [30].

The SGA is most common in otherwise healthy children between the ages of 2 and 5 years, but it can occur at any time from infancy to young adulthood [31].

Typically, it presents as a painless, immobile, solitary mass on the lower extremities, with normal overlying skin. Other, less frequent locations are upper extremities, buttocks, face and scalp. SGA will spontaneously regress without treatment and does not require biopsy or diagnostic imaging in clinically apparent cases. However, because of the subcutaneous location, clinical diagnosis can be difficult for non-dermatological specialists [32], which can result in a request for diagnostic imaging of a non-specific soft tissue mass.

Typically, GA appears on MR images (Fig. 9) as an illdefined lesion in the subcutaneous fat that does not extend to the deep tissues or fascia, isointense to muscle on T1-WI, and heterogeneous, predominantly hyperintense on T2-WI [33]. Degree and pattern of contrast enhancement are variable [34].

The most important clues for the radiologist to suggest SGA on MR imaging are the patient's age, location limited to subcutaneous tissue, indistinct lesion margins, and the previously mentioned signal characteristics on MR imaging. However, as imaging characteristics are non-specific, making the correct diagnosis in the absence of cutaneous abnormalities requires a biopsy.

\section{Inflammatory and infectious lesions}

\section{Rheumatoid nodules}

Rheumatoid nodules are granulomatous lesions with central areas of necrosis that occur in about $20 \%$ of patients with rheumatoid arthritis and less frequently in patients with rheumatic fever, systemic lupus erythematosus and ankylosing spondylitis [35].

These nodules can occur in the subcutaneous tissues in areas susceptible to trauma and in tissue overlying bursae, joints, tendons or ligaments. They are most common along the extensor side of the upper extremity. Less frequently they occur in the foot, typically at pressure points such as the heel pad and under the metatarsal heads.

MR imaging characteristics of rheumatoid nodules are non-specific (Fig. 10). They appear most commonly as illdefined nodular lesions isointense to muscle on T1-WI with heterogeneous intermediate-to-high SI on T2-WI. On contrast-enhanced MR images, rheumatoid nodules display varying patterns of contrast enhancement, ranging from homogeneous enhancement in solid lesions with no central necrotic areas to heterogeneous increased SI or faint peripheral enhancement in nodules with less or more advanced central necrosis [36, 37].

Diagnosis can be suggested if associated MR signs of inflammatory joint and bone disease are present (e.g. erosions, joint destruction, bone marrow oedema).

\section{Tenosynovitis}

Tenosynovitis involves inflammation of the tendon sheath. The aetiology may include acute and chronic trauma, infection or inflammatory or metabolic disease. Excessive 
Fig. 8 Epidermoid cyst (different patient from that in Fig. 7). Axial fat-suppressed T2-WI (a), coronal T1-WI (b) and coronal contrast-enhanced T1-WI (c). Unilocular, well-defined subcutaneous lesion (arrows) at the medial aspect of the ankle. The lesion has intermediate SI on T2-WI with some small areas of lower SI (probably due to keratinous debris), and is slightly hyperintense to muscle on T1-WI. A peripheral rim enhancement is seen (arrowhead), without internal enhancement
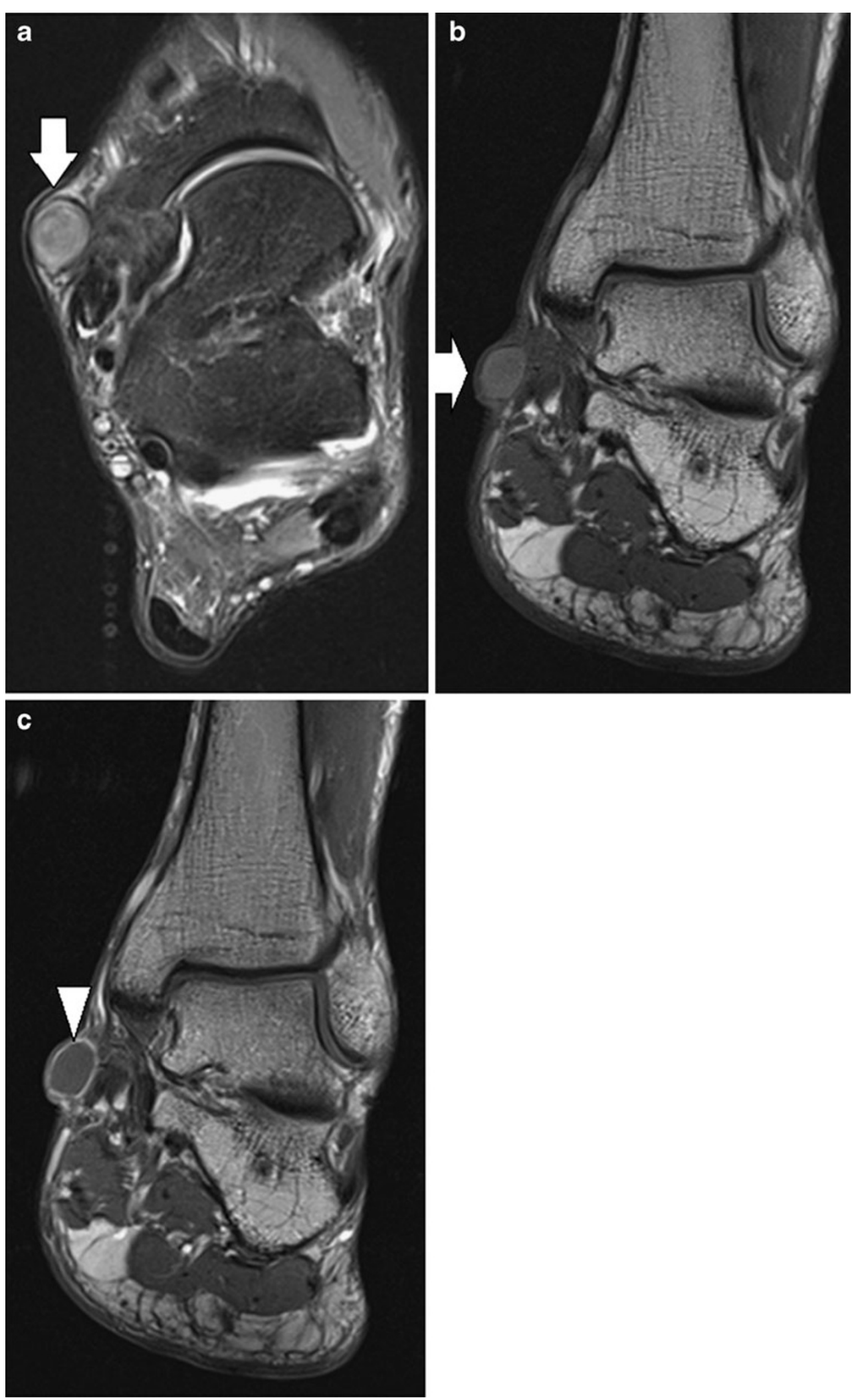

fluid accumulation in the tendon sheath can sometimes lead to a mass-like presentation [38].

Ultrasound examination reveals an effusion in the tendon sheath, along with thickening of the synovial lining.
Doppler signals in the synovium and the adjacent soft tissues may be increased [39].

MR imaging demonstrates a fluid collection in the tendon sheath with high SI on T2-WI and low SI on T1-WI (Fig. 11). 
Fig. 9 Granuloma annulare (combined cutaneoussubcutaneous presentation). A 14-year-old patient presenting with a round, erythematous skin lesion at the dorsum of the foot (a), with mild associated swelling. MR images: short axis T1-WI (b) and fat-suppressed T2-WI (c); short-axis (d) and sagittal (e) fat-suppressed contrast-enhanced T1-WI. Disc-like, ill-defined subcutaneous lesion at the dorsum of the foot. The lesion is iso-intense to muscle on T1-WI, is of high SI on T2-WI and demonstrates marked, slightly heterogeneous contrast enhancement
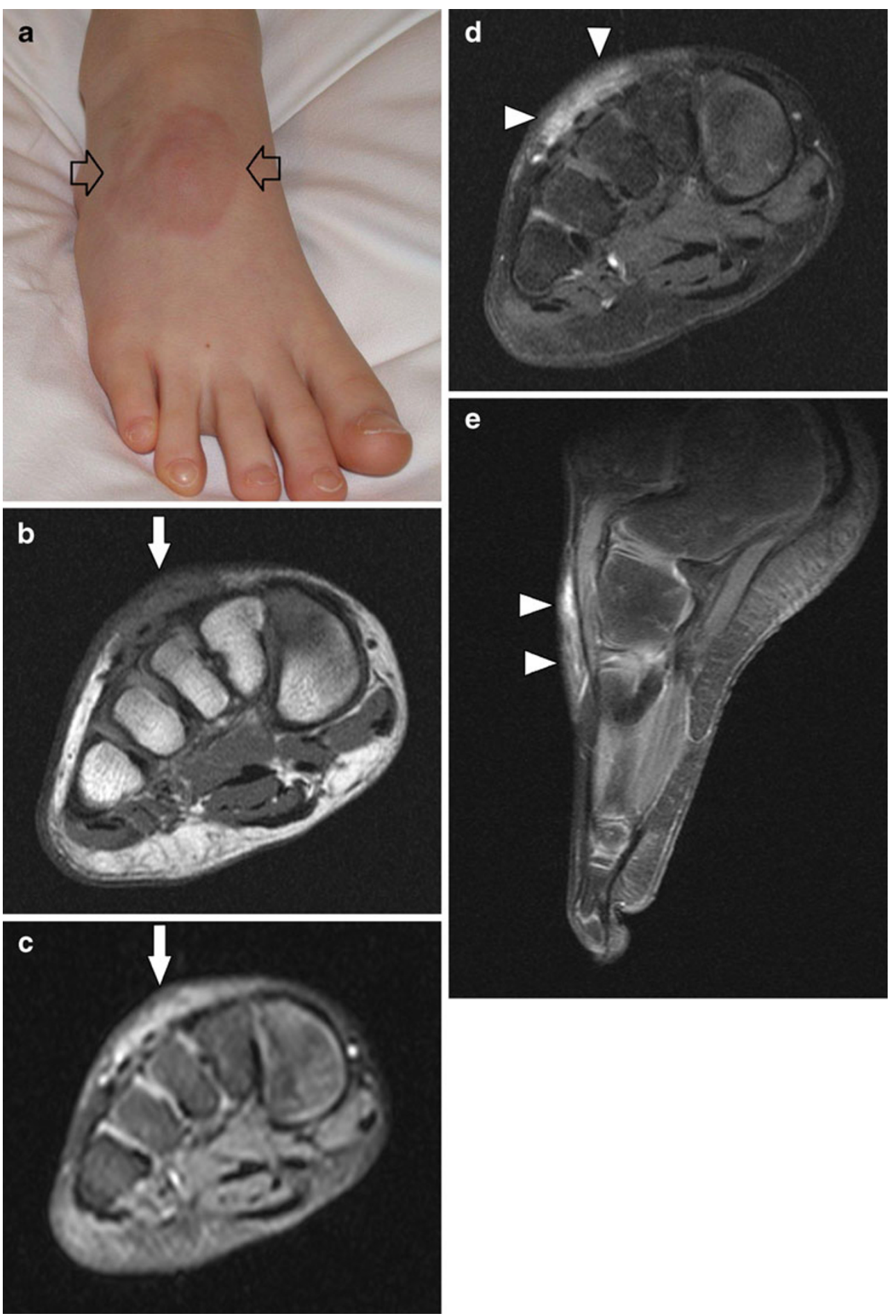

An abnormal thickening of the tendon sheath with enhancement after intravenous administration of gadolinium contrast medium may be seen. Associated signal alterations in the tendon indicate concomitant tendinosis [40].

\section{Abscess}

The primary cause of the development of an abscess in the foot is the infection of ulcers, which occur most frequently in diabetic patients. An abscess often communicates with sinus tracts that extend to bones, joints, tendon sheaths or skin ulceration. Clinically, associated cellulitis will be apparent. On MR imaging (Fig. 12), an abscess appears as a focal area isointense or hypo-intense to muscle on T1-WI, with fluid-equivalent (high) SI on T2-WI. There is thick rim enhancement after intravenous administration of gadolinium contrast medium [41]. Typically, there is evidence of adjacent soft tissue oedema. In diabetic patients, abscess formation is 

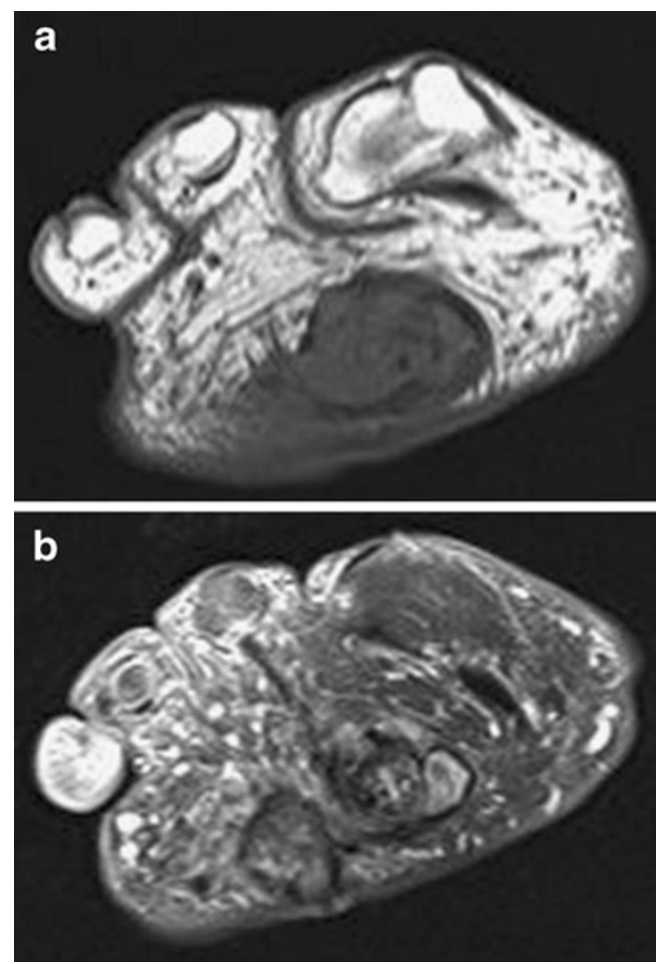

Fig. 10 Rheumatoid nodule. Short-axis T1-WI (a), fat-suppressed T2WI (b): nodular lesion at the plantar subcutaneous fat tissue at the level of the metatarsals. The lesion is of low SI on T1-WI, whereas heterogeneity is seen on T2-WI. Multiple erosions were seen at the metatarsophalangeal joints (not shown)

frequently associated with osteomyelitis and its characteristic bone marrow signal alterations [42].

\section{Metabolic disorders}

Gout

Tophaceous gout is a pseudotumoural process that usually manifests in later stages of gout arthritis. A gouty tophus is an amorphous or crystalline mass of urate with a surrounding layer of inflammatory tissue [43]. Lesions typically occur at the metatarsophalangeal or interphalangeal joints [44]. In rare cases extensive tophaceous gout can result in multiple soft tissue masses with destruction of multiple bones of the foot [45].

Clinical history, laboratory examination and radiographic findings will usually steer the clinician to the correct diagnosis of tophaceous gout, but occasionally a gouty tophus can mimic a neoplastic or infectious process, for which the referring clinician requests imaging studies.

Gouty tophi, like rheumatoid nodules, display nonspecific signal characteristics on MR imaging (Fig. 13): tophi typically are isointense to muscle on T1-WI, whereas the signal on $\mathrm{T} 2-\mathrm{WI}$ varies from being of homogeneous or
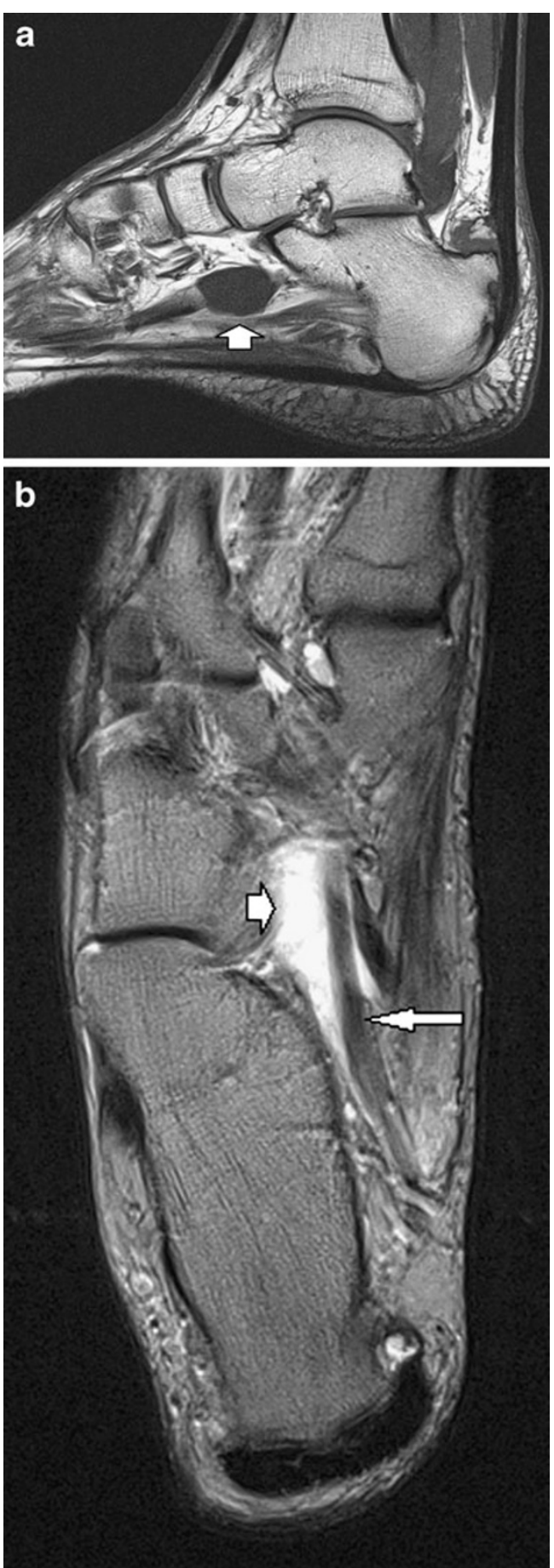

Fig. 11 Tenosynovitis of the flexor hallucis longus (FHL). Sagittal T1-WI (a) and long-axis T2-WI (b): there is marked effusion (short arrow) in the tendon sheath of the FHL (long arrow), of low SI on T1WI and high SI on T2-WI

heterogeneous high intensity to near-homogeneous low intensity [46]. This variability in SI on T2-WI could be due to differences in the amount of crystalline urate deposition, as well as the degree of calcification and fibrotic reaction. 

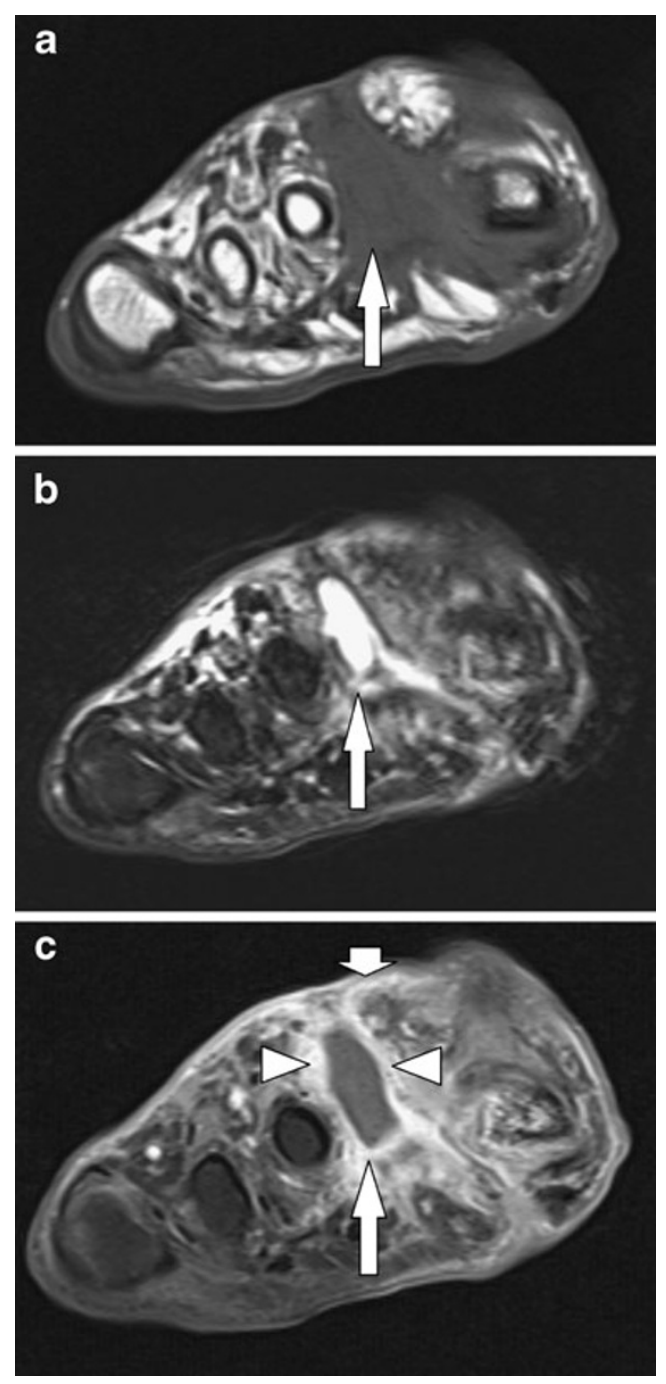

Fig. 12 Abscess. A 50-year-old diabetic patient, 2 years after amputation of the second digit (including the metatarsal head), presenting with a painless swelling at the region of previous surgery. Short-axis T1-WI (a), fat-suppressed T2-WI (b) and fat-suppressed contrast-enhanced T1-WI (c) demonstrate a collection (long arrow) in the soft tissue between the first and second metatarsal heads, of low SI on T1-WI, high SI on T2WI and thick rim enhancement (arrowheads). There is increased SI on T2-WI of the adjacent soft tissue and dermis as well as contrast enhancement, corresponding to oedema and cellulitis (short arrow)

On contrast-enhanced MR images, gouty tophi typically display a moderate to marked heterogeneous or nearhomogeneous enhancement [47].

\section{Tumoural calcinosis}

Tumoral calcinosis is a disease characterised by lobular, calcified soft tissue masses that occur in periarticular locations, especially the hip, elbow, shoulder, foot and wrist. The masses are often multiple and bilateral [48].

Tumoural calcinosis is usually classified as primary (idiopathic or familial) or secondary. The primary form typically presents with soft tissue masses in the first or
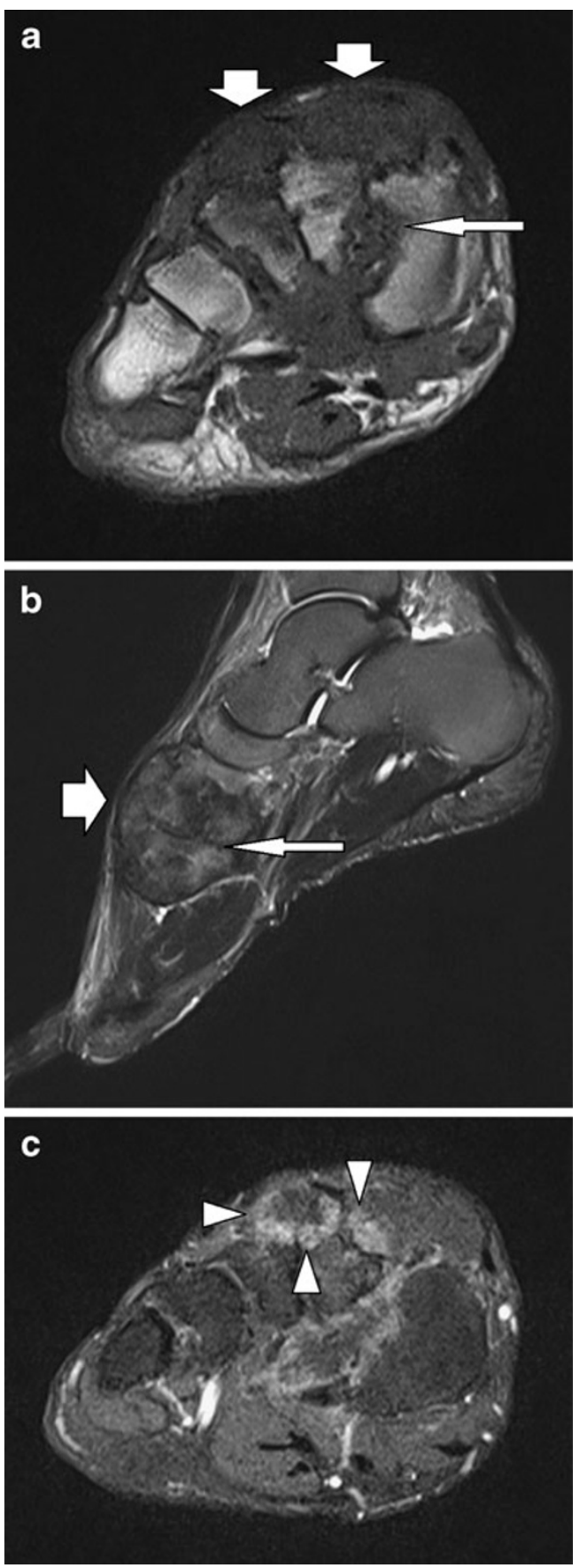

Fig. 13 Tophaceus gout. Short-axis T1-WI (a), sagittal fat-suppressed T2-WI (b) and short-axis fat-suppressed contrast-enhanced T1-WI (c): The gouty tophus (short arrows) is isointense to muscle on T1-WI and of heterogeneous SI on T2-WI. The lesion displays heterogeneous enhancement (arrowheads). There is evidence of erosive joint disease at the metatarsophalangeal joints (long arrows)

second decade of life, whereas the secondary form occurs mainly in patients with chronic renal failure, and has been attributed to secondary hyperparathyroidism [49].

On radiographs, tumoural calcinosis appears as multilobulated calcific deposits in a periarticular distribution, usually along the extensor surfaces of joints. The calcified 
masses may have a dense appearance or may contain fluidcalcium levels, known as the "sedimentation sign" [50]. Occasionally, pressure erosion on the underlying bone is seen [51].

MR examination is not required to make the diagnosis. If it is performed, tumoural calcinosis appears as a pseudotumour in periarticular regions with large septated regions of variable SI on both T1-WI and T2-WI [52].

Other metabolic disorders

Amyloidosis in rare cases results in the formation of pseudotumoural lesions at the foot and ankle. Amyloid deposition within the joint capsules or in the dermis can occasionally present as a soft tissue mass [53, 54]. Characteristically, the amyloid has a low SI on T1-WI, and a low to intermediate SI on T2-WI [55].

Tophaceous pseudogout caused by periarticular tumoural calcium pyrophosphate dehydrate (CPPD) or calcium hydroxyapatite (HA) deposition can occasionally mimic soft tissue or skeletal lesions [56]. On conventional radiography, the tophaceous lesions demonstrate calcification in a more granular and delicate pattern than the lobularappearing calcification of tumoural calcinosis. On MR imaging, signal intensities of pseudogouty tophi can vary from low to intermediate on T1-WI and from low to high on T2-WI. Often areas of low signal are seen, corresponding to calcifications [57].

\section{Miscellaneous disorders}

\section{Diabetic callus}

Soft tissue callus is a superficial soft tissue thickening that forms in response to mechanical pressure. Although benign and fairly common in the adult population, it occurs more often and builds up faster on the feet of diabetic patients. It develops in areas of abnormal weight-bearing and friction caused by diabetic foot deformities, and can eventually lead to ulceration and deeper infection.

Callus is commonly seen in the subcutaneous fat plantar to the first and fifth metatarsal heads.

On MR imaging, callus typically displays as an area in the plantar fat with low SI on T1-WI and low to intermediate SI on T2-WI (Fig. 14) [58]. After IV administration of gadolinium contrast medium low-level enhancement may be observed in and around callus [59].

Stress reaction and fracture

Post-traumatic bone abnormalities such as stress reactions and fractures may mimic a tumoural lesion of the ankle or
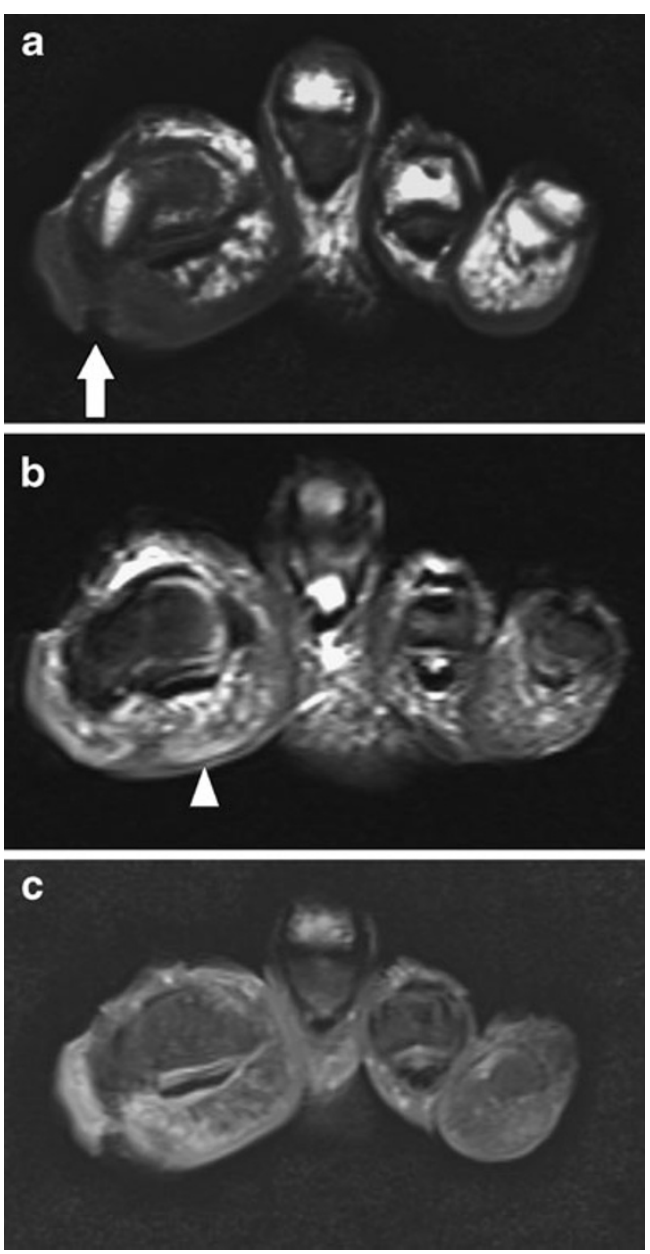

Fig. 14 Diabetic callus. Short-axis T1-WI (a), fat-suppressed T2-WI (b) and fat-suppressed contrast-enhanced T1-WI (c): callus with central ulceration (arrow) in the subcutaneous fat medial and plantar to the first metatarsal head, with low SI on T1-WI, intermediate SI on T2-WI and heterogeneous contrast enhancement. There is some oedema in the adjacent fat (arrowhead)

foot. A clinical history of a professional sporting activity or daily activity with increased stress on foot and/or ankle may aid in the diagnosis of such lesions.

Stress reaction in soft tissues around the ankle presenting as a tender mass has been described in figure skaters and professional snow boarders at the level of the shoe rim [60]. On MR imaging, these lesions appear as ill-defined mass-like regions iso-intense to muscle on T1-WI, with increased SI on T2-WI and enhancement after intravenous gadolinium contrast medium administration.

Occasionally, marked callus formation secondary to a (stress) fracture or metatarsal osteochondrosis may mimic an osseous and soft tissue mass of the foot [61]. A linear signal alteration in the bone marrow with low SI on T1-WI and high SI on T2-WI, which becomes more obvious with contrast enhancement and fat suppression, should lead to the diagnosis of stress fracture [62]. Periosteal callus formation associated with flattening of the head of the 
second metatarsal bone in an adolescent patient indicates a Freiberg's infraction (Fig. 15).

\section{Myositis ossificans}

Myositis ossificans (MO) is a benign condition of heterotopic bone formation, which can mimic soft tissue malignancy. It is very rarely seen in the foot and ankle region [63, 64]. Late-stage lesions display a zonal ossification pattern making diagnosis possible with conventional radiography [65]. Detailed discussion of the imaging features of $\mathrm{MO}$ is beyond the scope of this short review.

Plantar fibromatosis (Ledderhose disease)

The aetiology of plantar fibromatosis is still a matter of debate, but it is thought to represent a benign fibroblastic
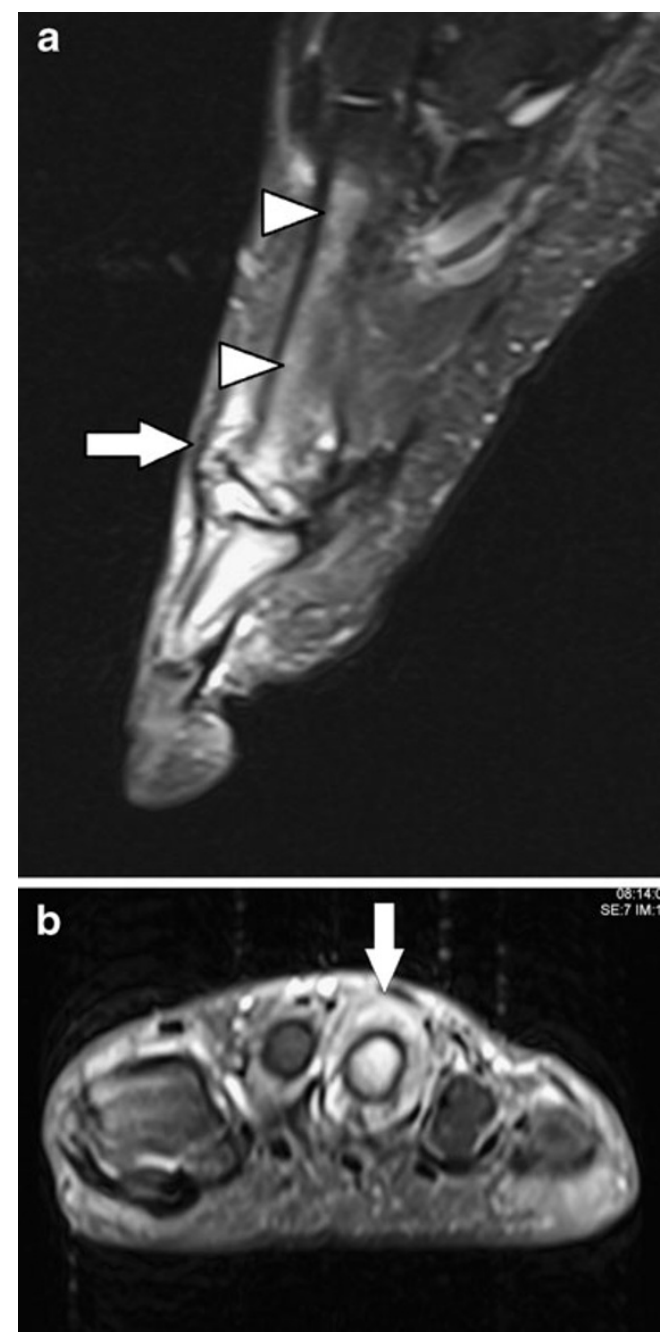

Fig. 15 Periosteal callus secondary to Freiberg's infraction. Sagittal (a) and short-axis (b) fat-suppressed T2-WI demonstrates flattening and deformation of the head of the second metatarsal bone with prominent periosteal callus formation (arrow) and bone marrow oedema (arrowheads) tumour, rather than a pseudotumour. Patients present clinically with painless, fixed, subcutaneous nodules on the sole of the foot, along the course of the plantar aponeurosis.

On ultrasound examination and MR imaging, plantar fibromatosis typically appears as a poorly defined mass in the deep aponeurosis in the medial aspect of the foot (Fig. 16). On both T1-WI and T2-WI the lesions are isointense or hypo-intense to skeletal muscle. Enhancement after IV gadolinium contrast medium administration is variable [66].
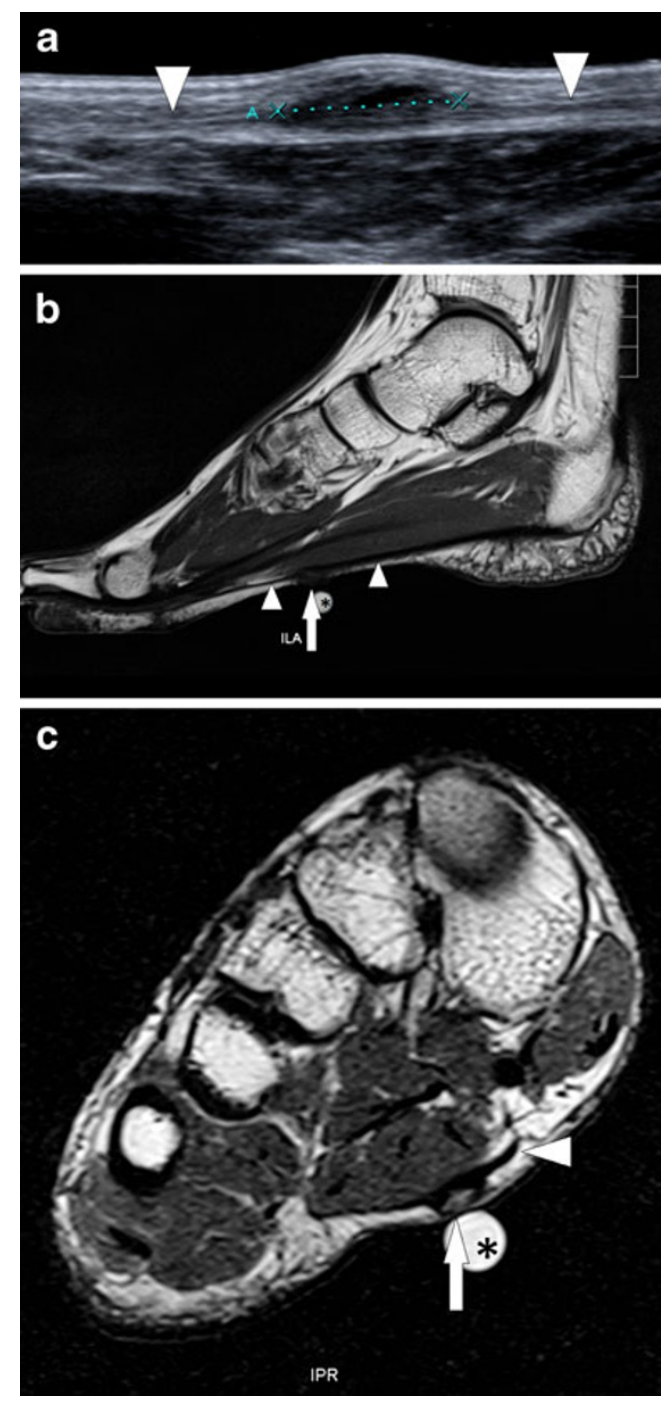

Fig. 16 Plantar fibromatosis. Patient with a painless subcutaneous nodule at the medial aspect of the foot sole. Ultrasound image (a) along the sagittal plane displays a hypo-echogenic ill-defined lesion at the medial bundle of the plantar aponeurosis, with a length of $11 \mathrm{~mm}$. Long-axis T1-WI (b) and short-axis T2-WI (c) clearly demonstrate the relationship between the lesion (arrow) and the plantar aponeurosis (arrowheads). The fibromatosis is iso-intense to muscle on T1-WI and slightly hyperintense on T2-WI. The nodular extracorporeal structure (asterisk) is an imaging marker placed on the skin for easy lesion localisation 
As plantar fibromatosis is considered to of a tumoural nature, detailed discussion of this entity and its imaging features is beyond the scope of this review.

\section{Conclusion}

The imaging features of pseudotumoural soft tissue lesions of the foot and ankle themselves are often non-specific, but in combination with exact location, the relationship with surrounding structures and clinical features such as sex, age and symptoms, the radiologist can usually suggest a specific diagnosis. The goal of imaging in the setting of pseudotumoural lesions is thus to confidently identify lesions that do not need further investigations and/or interventions (e.g. biopsy).

\section{References}

1. Sookur PA, Naraghi AM, Bleakney RR, Jalan R, Chan O, White LM (2008) Accessory muscles: anatomy, symptoms, and radiologic evaluation. Radiographics 28:481-499

2. Ho VW, Peterfy C, Helms CA (1993) Tarsal tunnel syndrome caused by strain of an anomalous muscle: an MRI-specific diagnosis. J Comput Assist Tomogr 17:822-823

3. Kinoshita M, Okuda R, Morikawa J, Abe M (2003) Tarsal tunnel syndrome associated with an accessory muscle. Foot Ankle Int 24:132-136

4. Vanhoenacker FM, Van de Perre S, De Vuyst D, De Schepper AM (2003) Cystic lesions around the knee. JBR BTR 86(5):302-304

5. Kliman ME, Freiberg A (1982) Ganglia of the foot and ankle. Foot Ankle 3(1):45-46

6. Steiner E, Steinbach LS, Schnarkowski P, Tirman PF, Genant HK (1996) Ganglia and cysts around joints. Radiol Clin North Am 34 (2):395-425

7. Omoumi $\mathrm{P}$, de Gheldere A, Leemrijse T, Galant C, Van den Bergh P, Malghem J, Simoni P, Vande Berg BC, Lecouvet FE (2010) Value of computed tomography arthrography with delayed acquisitions in the work-up of ganglion cysts of the tarsal tunnel: report of three cases. Skeletal Radiol 39(4):381-386

8. Graham CE, Graham DM (1984) Morton's neuroma: a microscopic evaluation. Foot Ankle 5:150-153

9. Wu KK (1996) Morton's interdigital neuroma: a clinical review of its etiology, treatment, and results. J Foot Ankle Surg 35(2):112119

10. Bencardino J, Rosenberg ZS, Beltran J, Liu X, Marty-Delfaut E (2000) Morton's neuroma: is it always symptomatic? AJR Am J Roentgenol 175:649-653

11. Soo MJ, Perera SD, Payne S (2010) The use of ultrasound in diagnosing Morton's neuroma and histological correlation. Ultrasound 18:14-17

12. Zanetti M, Strehle JK, Zollinger H, Hodler J (1997) Morton neuroma and fluid in the intermetatarsal bursae on MR images of 70 asymptomatic volunteers. Radiology 203:516-520

13. Torriani M, Kattapuram SV (2003) Dynamic sonography of the forefoot: the sonographic Mulder sign. AJR Am J Roentgenol 180:1121-1123

14. Zanetti M, Strehle JK, Kundert HP, Zollinger H, Hodler J (1999) Morton neuroma: effect of MR imaging findings on diagnostic thinking and therapeutic decisions. Radiology 213:583-588
15. Zanetti M, Weishaupt D (2005) MR imaging of the forefoot: Morton neuroma and differential diagnoses. Semin Musculoskelet Radiol 9(3):175-186

16. Chauveaux D, Le Huec JC, Midy D (1987) The supra-transverse intermetatarsocapital bursa: a description and its relation to painful syndromes of the forefoot. Surg Radiol Anat 9:13-18

17. Theumann N, Pfirrmann A, Chung CB, Mohana-Borges AV, Haghighi P, Trudell DJ, Resnick D (2001) Intermetatarsal spaces: analysis with MR bursography, anatomic correlation, and histopathology in cadavers. Radiology 221:478-484

18. Ashman C, Klecker R, Yu J (2001) Forefoot pain involving the metatarsal region: differential diagnosis with MR imaging. Radiographics 21:1425-1440

19. Resnick DR (1995) Articular anatomy and histology. In: Diagnosis of bone and joint disorders, 3rd edn. Saunders, Philadelphia, p 668

20. Jaffe HL (1972) Structure of joints, bursae mucosae, and tendon sheaths. In: Metabolic, degenerative, and inflammatory diseases of bones and joints. Lea \& Febiger, Philadelphia, pp 101-102

21. Brown RR, Rosenberg ZS, Schweitzer ME, Sheskier S, Astion D, Minkoff J (2005) MRI of medial malleolar bursa. AJR Am J Roentgenol 184:979-983

22. Studler U, Mengiardi B, Bode B, Schöttle PB, Pfirrmann CW, Hodler J, Zanetti M (2008) Fibrosis and adventitious bursae in plantar fat pad of forefoot: MR imaging findings in asymptomatic volunteers and MR imaging-histologic comparison. Radiology 246:863-870

23. Perse RM, Klappenbach RS, Ragsdale BD (1987) Trabecular carcinoma arising in the wall of an epidermal cyst. Am J Dermatopathol 9(5):423-427

24. Llauger J, Palmer J, Monill JM, Fraquet T, Bagué S, Rosón N (1998) MR imaging of benign soft-tissue masses of the foot and ankle. Radiographics 18:1481-1498

25. Lee HS, Joo KB, Song HT, Kim YS, Park DW, Park CK, Lee WM, Park YW, Koo JH, Song SY (2001) Relationship between sonographic and pathologic findings in epidermal inclusion cysts. J Clin Ultrasound 29(7):374-383

26. Hong SH, Chung HW, Choi J, Koh YH, Choi JA, Kang HS (2006) MRI findings of subcutaneous epidermal cysts: emphasis on the presence of rupture. AJR Am J Roentgenol 186:961-966

27. Shibata T, Hatori M, Satoh T, Ehara S, Kokubun S (2003) Magnetic resonance imaging features of epidermoid cyst in the extremities. Arch Orthop Trauma Surg 123(5):239-241

28. Fisher AR, Mason PH, Wagenhals KS (1998) Ruptured plantar epidermal inclusion cyst. AJR Am J Roentgenol 171:1709-1710

29. Harish S, Jan E, Ghert M, Alowami S, Finlay K (2006) Pseudotumoral appearance of a ruptured epidermal cyst in the foot. Skeletal Radiol 35(11):867-871

30. Letts M, Carpenter B, Soucy P, Davidson D (2000) Subcutaneous granuloma annulare of the extremities in children. Can J Surg $43: 425-430$

31. Navarro O, Laffan EE, Ngan BY (2009) Pediatric soft-tissue tumors and pseudo-tumors: MR imaging features with pathologic correlation. Radiographics 29:887-906

32. Davids JR, Holman BH, Billman GF, Krous JF (1993) Subcutaneous granuloma annulare: recognition and treatment. J Pediatr Orthop 13:582-586

33. Vandevenne JE, Colpaert CG, De Schepper AM (1998) Subcutaneous granuloma annulare: MR imaging and literature review. Eur Radiol 8 (8):1363-1365

34. Chung S, Frush DP, Prose NS, Shea CR, Laor T, Bisset GS (1999) Subcutaneous granuloma annulare: MR imaging features in six children and literature review. Radiology 210:845-849

35. Boutry N, Flipo RM, Cotten A (2005) MR imaging appearance of rheumatoid arthritis in the foot. Semin Musculoskelet Radiol 9 (3):199-209 
36. Sanders TG, Linares R, Su A (1998) Rheumatoid nodule of the foot: MRI appearances mimicking an indeterminate soft tissue mass. Skeletal Radiol 27:457-460

37. El-Noueam KI, Giuliano V, Schweitzer ME, O'Hara BJ (1997) Rheumatoid nodules: MR/pathological correlation. J Comput Assist Tomogr 21(5):796-799

38. Webster FS (1968) Peroneal tenosynovitis with pseudotumor. J Bone Joint Surg 50:153-157

39. Michelson J, Dunn L (2005) Tenosynovitis of the flexor hallucis longus: a clinical study of the spectrum of presentation and treatment. Foot Ankle Int 26(4):291-303

40. Bouysset M, Tavernier T, Tebib J, Noel E, Tillmann K, Bonnin M, Eulry F, Bouvier M (1995) CT and MRI evaluation of tenosynovitis of the rheumatoid hindfoot. Clin Rheumatol 14 (3):303-307

41. Tan PL, Teh J (2007) MRI of the diabetic foot: differentiation of infection from neuropathic change. Br J Rad 80:939-948

42. Unger E, Moldofsky P, Gatenby R, Hartz W, Broder G (1988) Diagnosis of osteomyelitis by MR imaging. AJR Am J Roentgenol 150:605-610

43. Robbins SL (1984) Gout and gouty arthritis. In: Robbins SL, Cotran RS, Kumar V (eds) Pathologic basis of disease, 3rd edn. Saunders, Philadelphia, pp 1356-1361

44. Bousson V, Hamzé B, Wybier M, Daguet E, Parlier C, Petrover D, Bossard P, Laredo JD (2008) Soft tissue tumors and pseudotumors of the foot and ankle. J Radiol 89:21-34

45. Johnson S, Toms A, Lee P (2003) Tophaceous gout: uncommon presentation of a common disease. J Rheumatol 30(4):863-864

46. Ko KH, Hsu YC, Lee HS, Lee CH, Huang GS (2010) Tophaceous gout of the knee: revisiting MRI patterns in 30 patients. J Clin Rheumatol 16(5):209-214

47. Yu JS, Chung C, Recht M, Dailiana T, Jurdi R et al (1997) MR imaging of tophaceous gout. AJR Am J Roentgenol 168:523-527

48. Martinez S, Volger JB, Harrelson JM, Lyles KW (1990) Imaging of tumoral calcinosis: new observations. Radiology 174:215-222

49. Franco M, Van Elslande L, Passeron C (1997) Tumoral calcinosis in hemodialysis patients: a review of three cases. Rev Rhum Engl 64:59-62

50. Hug I, Guncaga J (1974) Tumoral calcinosis with sedimentation sign. Br J Radiol 47:734-736

51. Mohamed S, Jong-Hun J, Weon-Yoo K (2007) Tumoral calcinosis of the foot with unusual presentation in an 11-year-old boy: a case report and review of literature. J Postgr Med 53:247-249
52. Steinbach LS, Johnston JO, Tepper EF, Honda G, Martel W (1995) Tumoral calcinosis: radiologic-pathologic correlation. Skeletal Radiol 24:573-578

53. Kransdorf MJ, Murphey MD (2006) Imaging of soft tissue tumors, 2nd edn. Lippincott, Philadelphia, pp 529-350

54. Borrowman TA, Lutz ME, Walsh JS (2003) Cutaneous nodular amyloidosis masquerading as a foot callus. J Am Acad Dermatol 49(2):307-310

55. Otake S, Tsuruta Y (1998) Amyloid arthropathy of the hip joint: MR demonstration of presumed amyloid lesions in 152 patients with long-term hemodialysis. Eur Radiol 8(8):1352-1356

56. Coombs RJ, Padanilam TG, Phillips E (2002) Tumoral pseudogout of the metatarsal. Skelet Radiol 31:39-42

57. Mizutani H, Ohba S, Mizutani M (1998) Tumoral calcium pyrophosphate dehydrate deposition disease with bone destruction in the shoulder: CT and MRI findings in two cases. Acta Radiol 39:269-272

58. Schweitzer ME, Morrison WB (2004) MR imaging of the diabetic foot. Radiol Clin North Am 42(1):61-71

59. Russell J, Peterson J, Bancroft L (2008) MR imaging of the diabetic foot. Magn Reson Imaging Clin N Am 16(1):59-70

60. Anderson SE, Weber M, Steinbach LS, Ballmer FT (2004) Shoe rim and shoe buckle pseudotumor of the ankle in elite and professional figure skaters and snowboarders: MR imaging findings. Skeletal Radiol 33:325-329

61. Kiter E, Yagci B, Duzcan E (2005) Callus formation of the tibial hallux sesamoid mimicking a bone tumor. J Am Podiatr Med Assoc 95(6):580-582

62. Anderson SE, Davies AM (2007) Pseudotumors in sports. In: Vanhoenacker F, Maas M, Gielen JL (eds) Imaging of orthopedic sports injuries. Springer, Berlin Heidelberg New York, pp 103-118

63. Todd W, Gianfortune PJ, Laughner T (2007) Post-traumatic myositis ossificans circumscripta: an unusually large example. J Am Podiatr Med Assoc 97(3):229-233

64. Allard MM, Thomas RL, Nicholas RW Jr (1997) Myositis ossificans: an unusual presentation in the foot. Foot Ankle Int 18(1):39-42

65. Wang XL, Malghem J, Parizel PM, Gielen JL, Vanhoenacker F, De Schepper AMA (2003) Pictorial essay: myositis ossificans circumscripta. JBR BTR 86:278-285

66. Robbin MR, Murphey MD, Temple HT, Kransdorf MJ, Choi JJ (2001) Imaging of musculoskeletal fibromatosis. Radiographics 21:585-600 